Note

\section{Appearance of a 38,000-dalton Com- ponent Possibly Associated with the Post-mortem Tenderization of Rainbow Trout Muscle}

\author{
Haruhiko Toyohara, Masashi Ando \\ and Yutaka SHIMIzU \\ Laboratory of Fishery Chemistry, \\ Department of Fisheries, Faculty of Agriculture. \\ Kyoto University, Kitashirakawa. Sakyo-ku, \\ Kyoto 606, Japan
}

Received November 30, 1989

Japanese have a long history of eating raw fish meat as sushi or sashimi. Recently, these foods have come to be commonly accepted especially in the United States and some European countries. For such raw fish meat, texture is a particularly important factor to evaluate its quality as well as taste. It is generally accepted that the toughness of fish muscle decreases more readily than that of mammalian and chicken muscle after death. However, only few studies have been done on the post-mortem tenderization of fish muscle in comparison with that of mammals or chicken.

Makinodan et al. ${ }^{11}$ and Seki and Watanabe ${ }^{2 /}$ showed that some proteolytic degradation might occur in the postmortem muscle of carp, Cyprinus carpio, based on the changes of banding patterns in sodium dodecyl sulfate polyacrylamide gel electrophoresis (SDS-PAGE). How- ever, it should be stressed that these studies were done on fish stored at high temperatures, $37^{\circ} \mathrm{C}^{1)}$ and $25^{\circ} \mathrm{C}^{2)}$

In contrast to these studies, no corresponding change in the SDS-PAGE pattern was observed for the muscle of tilapia, Oreochromis niloticus, a tropical fish, even after storage at $30 \mathrm{C}$ for 4 days. ${ }^{3 \prime}$ In this fish, however, tenderization actually proceeded during ice storage, ${ }^{3 /}$ and was accelerated at higher temperatures, suggesting the involvement of some biochemical changes. Therefore, attempts were made to examine the proteolysis of fish muscle proteins in association with the post-mortem tenderization by two-dimensional gel electrophoresis (2DGE) with silver staining this time.

Rainbow trout, Salmo gairdneri ( $480 \mathrm{~g}$ in body weight) was obtained alive. After being killed by decapitation, the

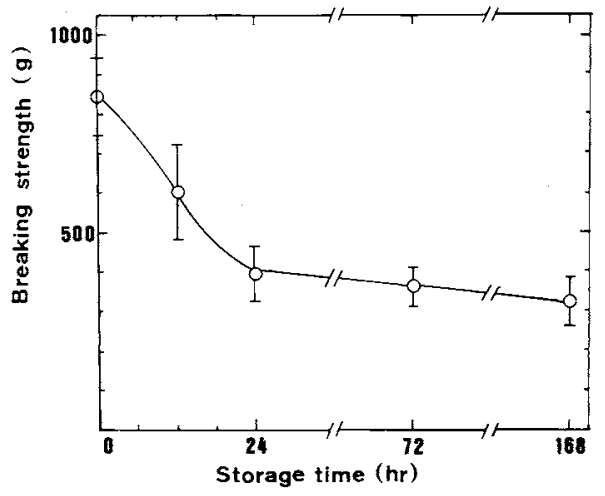

Fig. 1. Change of Toughness of Rainbow Trout Muscle during Storage at $4^{\circ} \mathrm{C}$.

Toughness was measured as breaking strength as described in the text. Values are expressed as means of $6-8$ measurements \pm S.D.

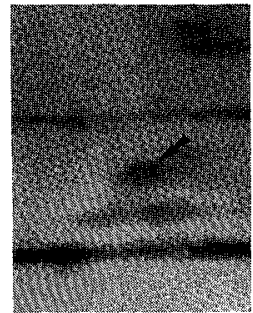

A

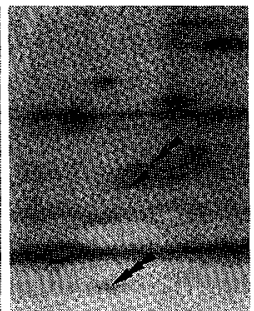

B

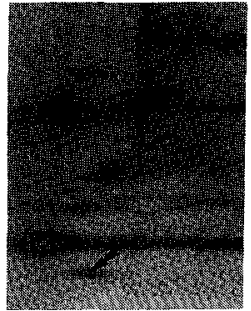

C

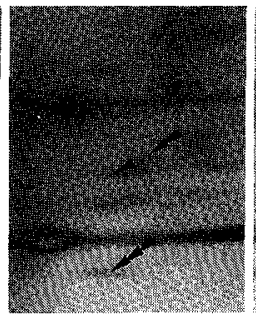

D

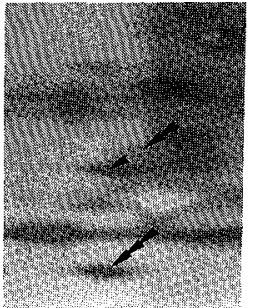

$\mathbf{E}$

Fig. 2. Two-dimensional Gel Electrophoretic Analysis of Post-mortem Rainbow Trout Muscle.

The first dimensional gel electrophoresis was done in a capillary column. The gel composition was $1 \%$ Agarose IEF (Pharmacia LKB Biotechnology) containing 12\% sorbitol, $6 \mathrm{~m}$ urea, 20\% Nonidet-P40, $1.5 \% 3-\{(3-$ cholamidopropyl)dimethylammonio)-1-propanesulfonate, and 2.3\% Ampholine (Pharmacia LKB Biotechnology). The Ampholine was a mixture of " $\mathrm{pH} 9-11$ " and " $\mathrm{pH} 7-9$ " in equal volumes. The second dimensional gel electrophoresis was done in a $10 \%$ polyacrylamide slab gel. Gels were stained with silver. Single-headed, double-headed, and triple-headed arrows indicate the $38 \mathrm{k}, 40 \mathrm{k}$, and $20 \mathrm{k}$ components, respectively. From left to right, myofibrillar fraction prepared immediately after death (A), and the fraction prepared from the fillet after storage at $4^{\circ} \mathrm{C}$ for $12 \mathrm{hr}(\mathrm{B}), 24 \mathrm{hr}(\mathrm{C}), 72 \mathrm{hr}(\mathrm{D})$, and $168 \mathrm{hr}(\mathrm{E})$. 
fish was filleted, and each fillet was packed in a plastic bag and stored at $4^{\circ} \mathrm{C}$. Fillets were taken out at selected times and used to prepare a myofibrillar fraction as described by Fukazawa $e t a l^{4}$ To the portion was added 10 volumes of cold $6 \mathrm{M}$ urea and it was homogenized. To $900 \mu \mathrm{l}$ of the homogenate were added $100 \mu$ of $10 \%$ SDS and $50 \mathrm{~mm} 2-$ mercaptoethanol, the mixture was heated at $95^{\circ} \mathrm{C}$ for 2 min, and used for 2DGE by the method of O'Farrell. ${ }^{5}$

The toughness of muscle was measured as breaking strength by a theometer (Yamaden RE-3305). A slice $10 \mathrm{~mm}$ thick was excised from the fillet perpendicular to the orientation of the muscle fibers. A column type plunger $(8 \mathrm{~mm}$ in diameter) penetrated into the slice parallel to the orientation of muscle fibers at a speed of $1 \mathrm{~mm} / \mathrm{s}$ and the breaking strength $(\mathrm{g})$ was recorded. The value was expressed as the average of $6-8$ measurements \pm S.D.

Figure I shows the change of toughness of rainbow trout muscle during storage at $4 \mathrm{C}$. The toughness decreased, sharply until $24 \mathrm{hr}$ after death and then gradually until at least the $168 \mathrm{th} \mathrm{hr}$.

In the 2DGE pattern (Fig. 2), a new spot appeared during storage. The isoelectric point and molecular weight of this protein were estimated to be 8.0 and 38,000 , respectively. The appearance of the $38 \mathrm{k}$ component was highly reproducible. The same to similar components were also observed in the post-mortem muscle of several species including tilapia and Amago salmon (Oncorhynchus masou macrostomus) (data not shown). Because the appearance of the $38 \mathrm{k}$ component seemed to accompany the decrease of a $40 \mathrm{k}$ component as observed in prolonged storage muscle, the former component could be a breakdown product of the latter. Based on all these results, it was assumed that the appearance of the $38 \mathrm{k}$ component is related to the post-mortem tenderization of muscle. In addition, appearance of a $20 \mathrm{k}$ component was noted during storage. Its involvement in the tenderization of muscle during storage was not clear, because the $20 \mathrm{k}$ component was often detectable immediately after death.

The $38 \mathrm{k}$ component did not appear when the myofibrillar fraction, not the whole muscle, was stored, suggesting the involvement of a sarcoplasmic factor, presumably proteolytic enzyme(s), in formation of the $38 \mathrm{k}$ component.

Appearance of a $30 \mathrm{k}$ component accompanying the degradation of troponin $T$ is generally observed in postmortem mammalian and chicken muscles. "' Based on the isoelectric point and molecular weight, the $40 \mathrm{k}$ component detected in our study may be troponin $T$. Further studies are required to substantiate this.

\section{References}

1) Y. Makinodan, M. Hirotsuka and S. Ikeda, Nippon Suisan Gakkaishi (formerly Bull. Japan. Soc. Sci. Fish.), 46, 1507 (1980).

2) N. Seki and T. Watanabe, Nippon Suisan Gakkaishi (formerly Bull. Japan. Soc. Sci. Fish.), 48, 517 (1982).

3) H. Toyohara and Y. Shimizu, Nippon Suisan Gakkaishi (formerly Bull. Japan. Soc. Sci. Fish.), 54, 1795 (1988).

4) T. Fukazawa, Y. Hashimoto and Y. Tonomura, Biochim. Biophys. Acta, 75, 234 (1963).

5) P. H. O'Farrel, J. Biol. Chem., 250, 4007 (1975).

6) M. Bito, K. Yamada, Y. Mikumo and K. Amano, Bull. Tokai Reg. Fish. Res. Lab. 109, 89 (1983).

7) I. F. Penny, "Development in Meat Science," Vol. 1, ed. by R. Lawrie, Applied Science Publishers, 1980, pp. 115-143. 